\title{
MANAJEMEN KELAS DALAM PEMBELAJARAN PAK ( UPAYA MENCIPTAKAN SUASANA BELAJAR-MENGAJAR INOVATIF)
}

\author{
Jack M Wenno \\ jackweno814@gmail.com
}

\begin{abstract}
The new paradigm of education requires that a teacher in general and specifically PAK teachers must improve classroom governance properly and creatively. Therefore, a class management with an innovative atmosphere is needed. This effort was made to improve the quality of learning in the classroom and encourage students to learn. For this reason, classroom management relating to classroom management is important to support an effective teaching and learning environment in the classroom. Therefore, a teacher must avoid the conventional habits or old ways, do not always pay attention to classroom management, this is very influential on the teacher's teaching style and learning styles of students.
\end{abstract}

Key words: Classroom management, PAK learning, innovative teaching and learning.

\section{Pengantar}

A. PENDAhuluan

Paradigma baru dalam sistem pendidikan modern turut merobah tata kelola pendidikan secara nasional. Sebagai contoh dengan diberlakukannya Kurikulum 2013 merupakan satu bukti bahwa paradigma baru pendidikan sudah maju seiring dengan kemajuan di bidang teknologi. Oleh karena itu, kita sebagai guru tidak dapat menutup mata dan atau tidak mempedulikan kemajuan di bidang pendidikan tersebut. Pengembangan model pembelajaran modern (inovatif) sebagai akibat positif dari perkembangan pendidikan modern. Modelmodel pembelajaran modern seperti yang diperkenalkan oleh Melvin Silberman merupakan sebuah contoh nyata bagaimana seorang guru PAK memadukan berbagai pendekatan mengajar dengan menggunakan pola atau model mengajar. Mau atau tidak mau, suka ataupun tidak suka, sudah menjadi tuntutan bagi seorang guru untuk dapat menciptakan kelasnya kreatif dan memberikan nuansa baru untuk belajar-mengajar dengan sukses. Oleh karena itu, guru PAK dituntut untuk mampu mengelola kelasnya, disinilah seorang guru tugasnya sebagai disainer kelas, fasilitator, organisator, motifator, dan inspirator.

Menurut Melvin bahwa untuk mengorganisir dan memfasilitasi kegiatan belajar aktif ini dimaksudkan untuk membantu para guru mengidentifikasi beberapa pilihan yang tersedia bagi mereka beberapa hal yang berbeda dalam rangka mengembangkan belajar aktif. Selanjutnya dikatakan bahwa banyak di antara gagasan ini yang sudah dikenal luas, dan Anda barangkali telah menggunakannya beberapa di antaranya. Namun saya berharap agar pekerjaan Anda dalam memfasilitasi kegiatan belajar aktif akan menjadi lebih mudah setelah menyusun daftar gagasan itu. Anggaplah daftar itu sebagai menu mengajar yang bisa Anda gunakan untuk menyeleksi pilihan Anda perlu pada saat tertentu guna menjadikan belajar sebagai kegiatan aktif(Siberman:2009).

Untuk menjalankan proses pembelajaran aktif di kelas maka diperlukan manajemen kelas yang professional dalam tata kelola kelas. Untuk hal dimaksud, maka membutuhkan daya kreasi guru yang inspiratif. Seorang guru PAK harus memiliki ciri-ciri yang seperti diuraikan di atas. Paling tidak, ada sepuluh tata letak untuk menyusun kelas. Jadi, manajemen kelas adalah sebuah seni dari guru untuk mengelola kelas. Berkaitan dengan itu, maka menurut Follet yang dikutip oleh Syaiful karena manajemen mencapai sasaran melalui cara-cara dengan mengatur orang lain menjalankan dalam tugas. Sedangkan dikatakan sebagai frofesi karena manajemen dilandasi oleh keahlian khusus untuk mencapai suatu prestasi manejer, dan para professional dituntun oleh suatu kode etik (Sagala:2013). Selanjutnya menurut Albert Lepawsky manajemen adalah tenaga, kekuatan yang memimpin, memberi petunjuk, dan membimbing suatu organisasi dalam mencapai suatu tujuan yang telah ditentukan terlebih dahulu. 
Dengan demikian, lingkungan fisik dalam kelas dapat mendukung atau menghambat kegiatan belajar aktif. Penelitian berbagai tokoh untuk dapat disesuaikan dengan kebutuhan rencana pembelajaran yang mau dicapai sesuai dengan tujuan pembelajaran. Menurut Rusman ia mengatakan bahwa dalam melakukan kegiatan jenis ini guru harus mengetahui betul potensi anak didik. Karena berangkat dari potensi itulah guru menyiapkan strategi pembelajaran yang dirujuk dengan potensi anak $\operatorname{didik(Rusman:2011).~}$

Berkaitan dengan ulasan di atas, ada beberapa faktor penentu yang akan berpengaruh pada pola gaya belajar peserta didik di kelas yang diakibatkan oleh gaya mengajar guru. Faktor-faktor penentu tersebut antara lain: guru sebagai demonstrator, guru sebagai pengelola kelas, guru sebagai mediator, dan guru sebagai evaluator. Sejalan dengan pendapat di atas, maka menurut Sidjabat katakana bahwa kegiatan pembelajaran itu jelas melibatkan segala aspek, yaitu aspek manusiawi, material, fasilitas, perlengkapan, dan prosedur. Unsur manusiawi yang terlibat dalam aktivitas mengajar ialah guru dan murid. Artinya, guru mengajar dan murid belajar. Tidak mungkin guru mengajar tanpa peserta didik. Akan tetapi perlu kita perhatikan bahwa tentu saja murid dapat belajar sendiri atau bersama dengan rekan-rekannya tanpa kehadiran guru misalnya ketika mereka mempelajari literatur dan mendiskusikannya, pada waktu melakukan observasi di luar kelas, atau ketika merencanakan dan mewujudkan karya tulis(Sojabat:2011).

Dari berbagai penjelasan di atas dapat disimpulkan bahwa dalam mengorganisir kelas pada saat memulai pembelajaran itu sangat menentukan dan efektif karena bergantung pada strategi tata kelola kelas yang diambil oleh guru sebagai tindakan yang tertanggung jawab. Jadi, manajemen kelas dan tata kelola kelas yang dikelola guru sangat berperan dan menetukan kegiatan belajar-mengajar di kelas. Apapun upaya guru maksudnya untuk meminimalisasikan efektifitas dari pembelajaran di kelas. Untuk hal dimaksud maka guru harus punya ide-ide yang cemerlang.

\section{Tinjauan Literatur}

Banyak guru akan lebih mudah dan penuh semangat karena tidak mendapat kesulitan dalam mengelola kelasnya karena faham dalam memanfaatkan kelasnya sehingga menjadi sebuah suasana belajar-mengajar yang inovatif. Jika kelas ditata dengan baik, maka akan membantu mengefisiensikan waktu mengajar, penggunaan bahan ajar, alat dan perlengkapan belajar karena didukung oleh suasana kelas. Sebaliknya kalau tidak ditata pasti suasana belajar-mengajar seperti biasa-biasa saja dan suasananya terkesan pembelajaran konvensional.

Guru modern punya visi dan misi di kelas yang ia ajar, dan apa yang diajarkan harus berkesan dimata peserta didik. Guru modern adalah guru yang motivatif dan inspiratif terhadap peserta didiknya. Oleh karena itu, dituntut manajemen kelasnya harus oke dan tertanggung jawab. Guru modern harus jelas tata kelola kelasnya dan harus mencapai suasana pembelajaran PAIKEM GEMBROT. Jadi, prinsipnya manajemen kelas berkaitan dengan guru sebagai , organisator, fasilitator, motifator, dan inspirator dalam mendisainer kelas. Guru yang inovatif selalu memanfaatkan setiap kondisi untuk kepentingan belajar peserta didiknya. Guru yang inovatif selalu menghindari kebiasaan untuk mengabaikan manajemen kelas.

Ada banyak alasan guru bila ditanya kenapa tidak memanfaatkan ruang kelas dalam belajarmengajar? Jawaban guru mengorganisir kelas buang waktu dan buang tenaga. Kebiasaan seperti ini kita temui di lapangan bagi guru yang skeptis dan tidak pro-aktif. Penampilan dalam mengajar memberikan kesan bahwa yang dipentingkan materi bisa segera tuntas sesuai target, waktu efektif, dan menjawab beban kurikulum. Suasana seperti yang diungkapkan di atas, akan memberikan kesan untuk kita bahwa itulah guru yang konvensional, tidak mau maju (skeptis) dan tidak modern. Guru 
modern adalah guru yang berinovatif dan proaktif.

\section{Metode}

Dalam tulisan ini, penulis menggunakan metode penelitian tindakan kelas.

\section{Hasil dan Pembahasan}

Berikut ini akan dideskripsikan sepuluh tataletak kelola kelas sebagai berikut:

\section{Mengorganisir Kelas dalam Bentuk $U$}

Bentuk ini merupakan formasi serbaguna. Siswa bisa menggunakan permukaan meja untuk membaca dan menulis, dapat melihat Anda dan/ atau media visual Anda dengan mudah. Dengan formasi ini siswa juga dapat dengan mudah dipasangkan, khususnya bila ada dua tempat duduk per meja. Susunan atau formasi ini cocok untuk mendistribusikan buku pelajaran dengan cepat kepada siswa karena Anda dapat memasuki sisi dalam diri formasi bentuk-U ini dan berjalan menuju titik yang berbeda dengan membawa materi pelajaran. Anda dapat menata meja dan kursi menjadi formasi $\mathrm{U}$.

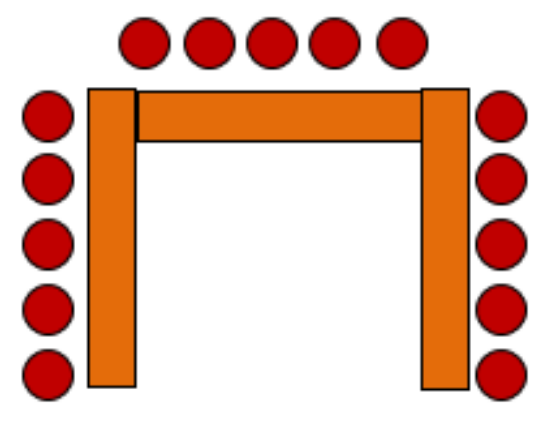

Pastikan bahwa ada terdapat cukup celacela di dalam ruang kelas agar sub-sub kelompok yang terdiri dari meja dan bertahap-tahap satu sama lain. Anda juga dapat menata meja dan kursi dalam bentuk U yang tampak seperti setengah lingkaran

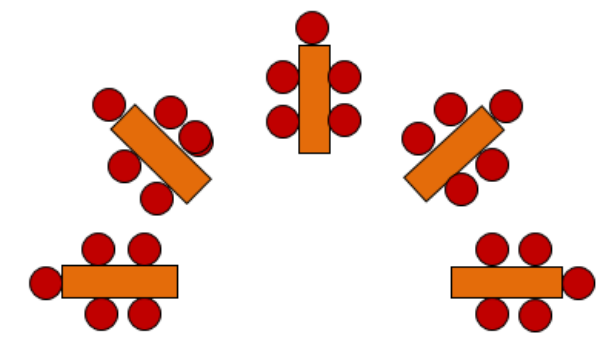

2. Mengorganisir Kelas Kelas dalam Bentuk Gaya Tim

Mengelompokkan meja secara melingkar di dalam ruang kelas memungkin Anda untuk meningkatkan interaksi tim. Anda dapat menempatkan meja untuk membentuk formasi yang paling akrap. Jika ini Anda lakukan, beberapa siswa harus memutar kursi mereka agar menghadap ke depan kelas supaya bisa melihat Anda dan papan tulis.
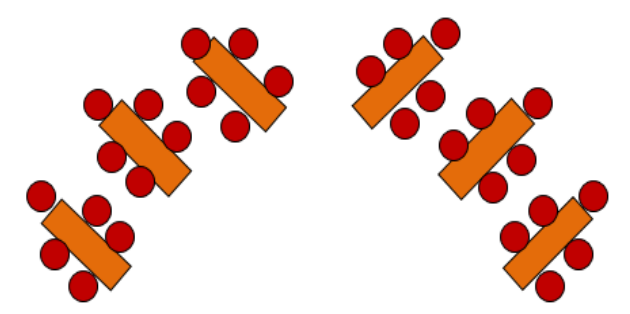

Anda dapat pula menyusun kursi dalam bentuk setengah lingkaran agar tidak ada siswa yang membelakangi ruang depan kelas.

\section{Mengorganisir Kelas dalam Bentuk Meja Konferensi}

Formasi ini sangat baik bila mejanya relatif budar atau persegi. Formasi ini menimbulkan dominasi guru dan memaksinalkan peran siswa. Meja berbentuk empat persegi panjang bisa menciptakan kesan formal jika guru berada diujung meja. 


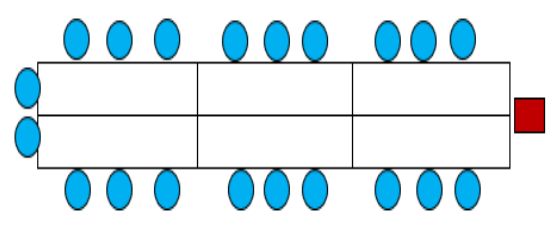

Jika guru duduk di tengah dari sisi yang lebih panjang, siswa yang berada di ujung akan merasa diabaikan.

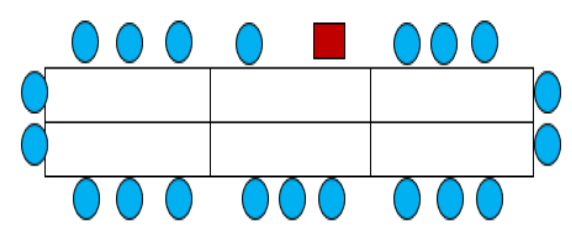

Anda dapat membentuk formasi meja konferensi dengan menggabungkan beberapa meja kecil (dan bagian tengahnya dikosongkan).

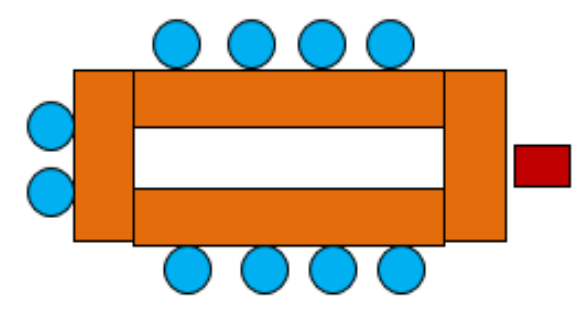

\section{Mengorganisir Kelas dalam Bentuk Lingkaran}

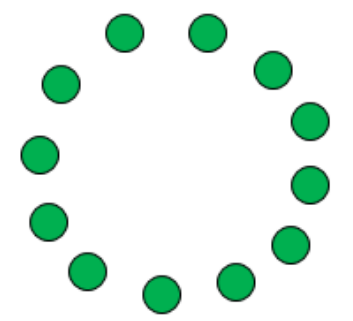

Jika Anda ingin menyediakan alas untuk menulis bagi siswa gunakan formasi alternatif. Perintahkan mereka untuk memutar kursi manakala Anda menghendaki diskusi kelompok.
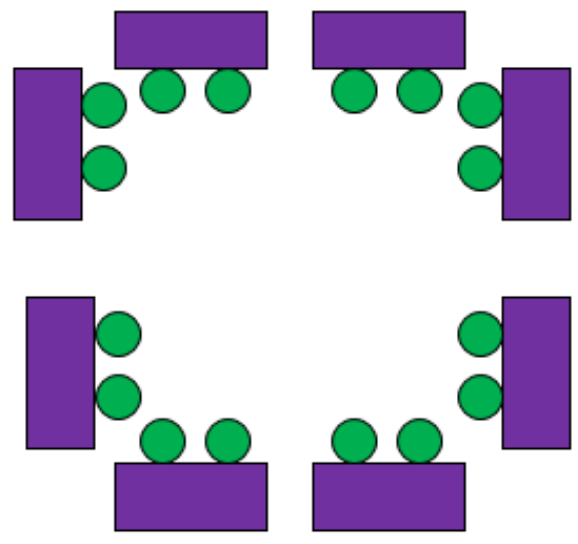

5. Mengorganisir Kelas dalam Bentuk Kelompok pada Kelompok

Formasi ini menunjukkan Anda untuk melakukan diskusi terbuka seperti membuat drama, debat atau melakukan pengamatan aktivitas kelompok. Disain yang paling umum terdiri dari formasi lingkaran kursi. Atau Anda dapat menempatkan meja konferensi di tengah-tengahnya, yang dikelilingi dengan kursi.

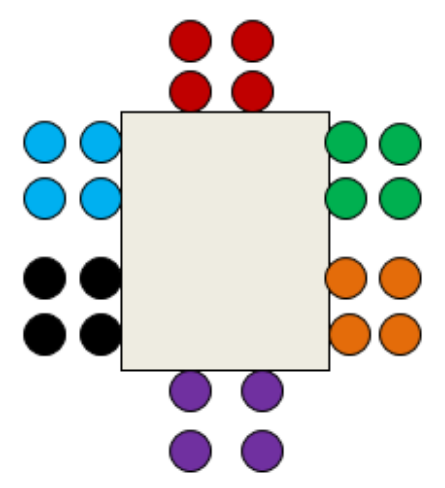

6. Mengorganisir Kelas dalam Bentuk Ruang Kerja

Formasi ini cocok untuk lingkungan aktif khas laboratorium di mana siswa duduk di ruang kerja untuk mengerjakan soal atau tugas (misalnya, hitung-menghitung, mengoperasikan mesin, melakukan kerja laboratorium) segerah setelah ditunjukkan caranya. Cara yang bagus untuk mendorong kemitraan dalam belajar dengan cara 
menempatkan dua siswa pada tempat kerja yang sama.

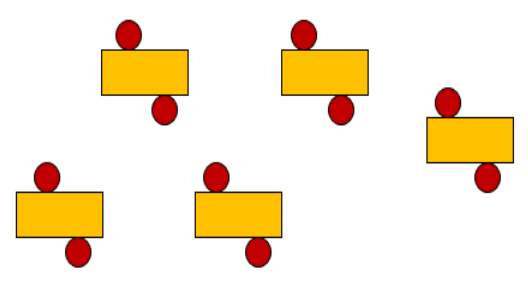

7. Mengorganisir Kelas dalam Bentuk Pengelompokan Berpencar

Jika ruang kelas Anda cukup besar atau jika tersedia tempat di ruangan sebelah, tempatkanlah (bila memungkinkan) meja dan/atau kursi yang bisa digunakan oleh sub-sub kelompok untuk melakukan aktivitas belajar berbasis-tim. Usahakan agar susunan berpencar ini cukup berjauhan agar tim-tim yang ada tidak saling mengganggu. Namun hindarilah pemencaran yang terlalu jauh agar tidak kesulitan untuk melakukan hubungan antar tim.

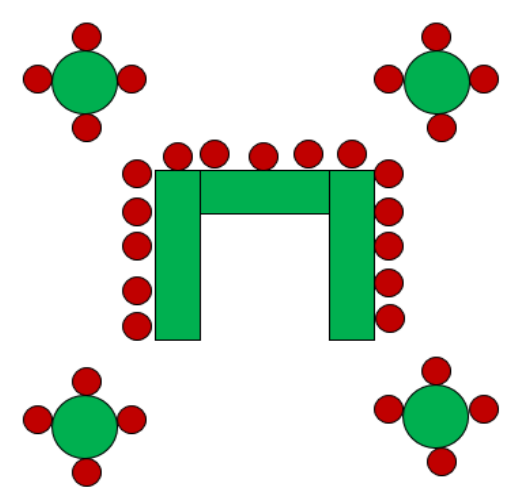

\section{Mengorganisir Kelas dalam Bentuk Formasi Tanda Pangkat}

Susunan ruang kelas tradisional (deretan meja kursi) tidak kondusif bagi pelaksanaan belajar aktif. Bila terdapat sejumlah siswa (30 atau lebih) dan yang tersedia hanya meja-kursi tradisional adakalanya perlu menata siswa dengan "gaya ruang-kelas $\mathrm{V}$ terbalik atau tanda pangkat dapat mengurangi jarak antara siswa, penglihatan yang lebih baik ke bagian depan kelas, dan lebih memungkinkan untuk melihat sesame siswa ketimbang bentuk deretan lurus. Dalam formasi ini, akan lebih baik bila di tengahnya diberi sela-sela untuk lewat.

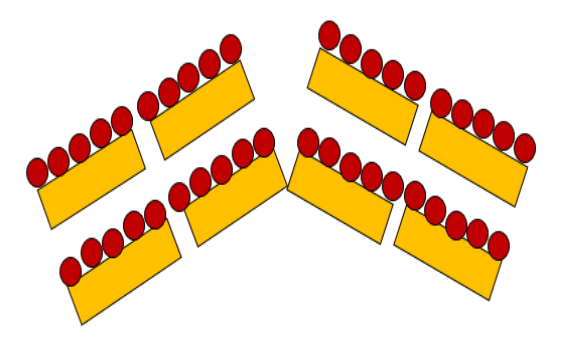

\section{Mengorganisir Kelas dalam Bentuk Ruang Kelas Tradisional}

Jika memang tidak memungkinkan untuk membuat formasi lengkung, cobalah untuk mengelompokkan kursi secara berpasangan untuk memungkinkan belajara secara berpasangan. Cobaalah membuat deretan dalam jumlah genap dan beri ruang yang cukup antara deret itu agar pasangan siswa dalam deret ganjil dapat memutar kursi dan menciptakan kuartet dengan pasangan yang duduk tepat di belakangnya, atau di deretan berikutnya.

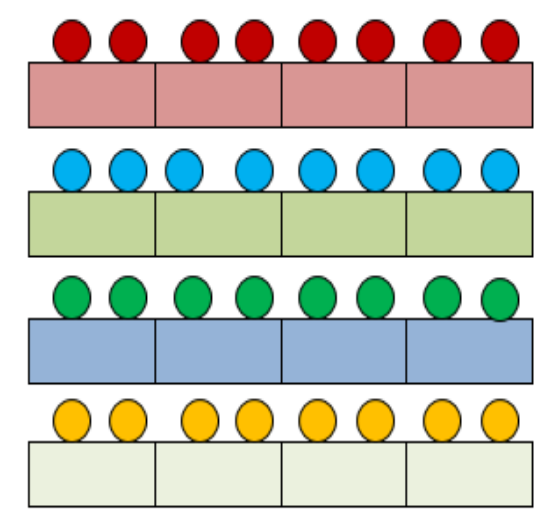

\section{Mengorganisir Kelas dalam Bentuk Auditorial}

Lingkungan auditorium memang kurang kondusif untuk kegiatan belajar aktif namun masih ada harapan untuk itu. Jika kursinya bisa dipindah, tempatkanlah dalam bentuk busur untuk menciptakan 
kedekatan dan siswa bisa melihat bagian depan kelas dengan lebih jelas.

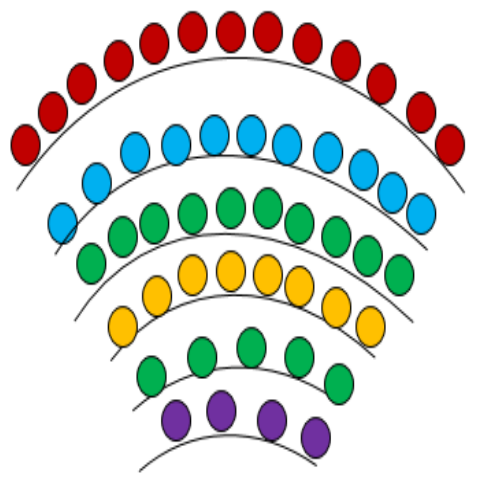

\section{Simpulan}

Dari berbagai penjelasan di atas, maka penulis dapat memberikan simpulan tentang pentingnya manajemen kelas sebagai berikut:

1) Guru yang professional dan modern mampu bertindak sebagai organisator kelas, fasilitator kelas, motivator kelas, dan inspirator kelas bagi peserta didik.

2) Guru yang baik, trampil, dan kreatif dapat menguasai tata kelola kelas sebagai strategi untuk membangun interaksi pembelajaran aktif.

3) Guru modern adalah guru yang inovatif dan kaya dengan berbagai model pembelajaran.

\section{Saran Dan Rekomendasi}

Dari hasil simpulan di atas dapat dikemukakan saran sebagai berikut:

1) Seorang guru PAK yang bertanggung jawab harus memiliki kemampuan untuk mengelola kelsnya secara kreatif.

2) Dalam mendesain rancangan pembelajaran yang bernuansa inovatif seorang guru PAK sudah harus punya ide untuk tata kelola kelas.

3) Mengelola kelas dengan baik berarti memberikan peluang untuk peserta didik berperan secara aktif dan memberikan suasana pembelajaran itu kreaktif dan inovatif..

\section{Ucapan Terima Kasih}

Pada kesempatan ini, terimakasih saya ucapkan kepada redaktur yang telah memberikan masukan yang berharga sehingga tulisan ini dapat disajikan di jurnal Institutio. Terimakasih juga saya ucapkan kepada seluruh dewan redaksi jurnal Institutio yang sudah memberikan ruang diskusi. Semoga bantuan dan dukungannya mendapatkan balasan yang sebanyak-banyaknya dari Tuhan kita Yesus Kristus, Amin.

\section{Pustaka Acuan}

Rusman. Model-Model Pembelajaran Mengembangkan Profesionalisme Guru. Jakarta: PT RajaGrafindo Persada, 2011.

Sagala, Syaiful, H. Manajemen Strategik dalam Peningkatan Mutu Pendidikan. Bandung: Penerbit Alfabeta, 2013.

Sidjabat, B,S. Mengajar Secara Professional.Bandung: Yayasan Kalam Hidup, 2011.

Silberman, Melfin, L. Active Learning 101 Cara Belajar Siswa Aktif. Bandung: Penerbit Nusamedia, 2009.

Trianto. Model-Model Pembelajaran Inovatif Berorientasi Konstruktivistik. Jakarta: Prestasi Pustaka Publisher, 2007.

Zaini, Hisyam, dkk. Strategi Pembelajaran Aktif. Yagyakarta: Insan Madani Islamic Publisher, 2008. 